\title{
Research on Emergency Management System for Military Engineering Projects
}

\begin{abstract}
Emergency management systems for military engineering projects have been established to enhance the capacities of wartime logistics and emergency logistical support. This study focuses on the combat characteristics of the warfare information system and based on analysis of emergency response for military combat systems, utilizes the concept of systematic combat and comprehensive integrated approach to investigate management of military engineering projects. Also, a basic mode for emergency management of military engineering projects based on the concept of "pre-war intelligent engineering on demand, wartime early engagement warning and monitoring, postwar emergency repair and rescue" and "strategic, comprehensive, integrated response" is proposed.
\end{abstract}

Keywords: military engineering projects, emergency management, system

\section{Introduction}

It is increasingly getting urgent to enhance wartime logistical and emergency logistical capabilities support to adapt to every new trend in military conflicts. In modern information-based warfare, early target discovery leads to quick destruction. China has established several military emergency defense systems, such as "comprehensive defense, active defense, and engineering defense" systems. But problems arise including how to effectively coordinate engineering defense with comprehensive defense measures, and how to integrate engineering defense systems into the overall military combat system. To solve these problems, emphasis must be placed on the construction and management of military defense projects and also on the

Manuscript received September 30, 2014; accepted December 27, 2014

Mao-guang Lin

Guangzhou Military Air Force Engineering Construction Bureau,

Guangzhou 510405, China

Qian-kun Wang $(\triangle)$

Wuhan University of Technology, Wuhan 430070, China

Email:wangqk@whut.edu.cn investigation of the emergency management system for military engineering projects.

\section{Theoretic analysis of emergency management for military engineering projects}

2.1 Guidance of systematic combat concept on emergency management for military engineering projects

\subsubsection{Functional requirements for information warfare}

In future warfare, the combatants may face threats from information technology-based surveillance and attack. With the extensive use of information technology in combat systems, surveillance and monitoring information can be automatically acquired, transmitted, processed, used, and then effectively interfaced with combat weapons to considerably increase the responsiveness to military attacks. Meanwhile, as far as an attack threat is concerned, the development of weaponry based on information technology imposes greater challenges on emergency management for military engineering projects due to greater attack precision and greater destruction capacity. Therefore, military engineering projects and related emergency management systems should be equipped with electronic countermeasures, as well as network attack and defense abilities.

2.1.2 Inherent need for counterwork of information-based system of systems

The term "system of systems" originally referred to an entirety made up set of objects within a certain range or objects of the same kind according to a certain order and inherent connection. It is defined by many scholars as "an assemblage of systems", i.e., complex giant system. System of systems refers to a system that consists of several independently operated and managed systems and is continuously adjusted and evolved in a man-in-the-loop manner to achieve certain capabilities. The difference 
between a system of systems and a system, was that not all complex giant systems or assemblage of systems are system of systems, only those complex giant systems or assemblages of systems that adequately reflect man's will, goal and intention can be called system of systems.

Information warfare is conflict between systems of systems. In the face of the integrated threats of surveillance and attack, only using "hidden" type defense and "resistant" type defense measures are insufficient to withstand massive strikes, and the internal and external connections of the defense system must be enhanced to form a huge cohesive force, as if making a fist with separate fingers. In other words, as an element of defense, military engineering projects and related emergency management systems should focus internally to integrate decisionmaking regarding the construction and operation of projects, and externally on combining emergency management with communication and command of the military projects that participate in warfare.

\subsubsection{Natural choice for systematic combat mode}

A systematic combat mode has distinct characteristics. First, systematic combat emphasizes multidimensional engagement, and focuses on integrating command with control to achieve seamless connections between information acquisition to commanding attack, as well as integrating combat forces to enhance their complementary advantages and extend the battlefield from physical space to virtual space. Second, systematic combat emphasizes the initiative of people and imposes stricter requirements on the overall quality and spontaneity of the decision-making abilities of individual military officers. Each person is a node on the warfare system network and his, or her initiative, creativity and motivation, directly affects success or failure. Third, systematic combat emphasizes the use of information advantage to strike first and defeat the enemy.

Systematic combat is a natural choice for modern warfare in which decision-making and command are based on information systems. It imposes great challenges on the engineering and emergency management of military projects as well as the combat capability of the resulting defense engineering system from the perspectives of information technology and systemization. Warfare is a territory full of uncertainty, contradiction, chance, luck, fear, danger and irrationality, which cannot be changed by technical advancements; emphasizing warfare also involves the "uncertainty factor" and "scientific decisionmaking" issues. Therefore, emergency management for military engineering projects must focus on solving the emergency response problems associated with scientific decision-making, information system engineering, and dynamic management of the defensive projects involved in systematic combat.
2.2 Connection between emergency management theory and emergency management for military engineering projects

\subsubsection{Concept of emergency management}

Emergency management is a method of effectively integrating various social resources, to effectively monitor, respond, control, and handle unexpected incidents in order to reduce the harm from sudden catastrophic incidents.

\subsubsection{Emergency management mode}

China has developed a 4R emergency management model, i.e., "reduction, readiness, response and recovery", and three-stage emergency response requirements, i.e., prevention before the emergency, response during the emergency and recovery after the emergency. The crisis cycle is divided into pre-crisis early warning, response during the crisis as well as post-crisis recovery and remedy. Emergency management methods mainly focus on creating emergency response plans, i.e., proposing emergency management, command and rescue plans before unexpected incidents, and implementing rescue according to corresponding plans in the event of a disaster or crisis.

\subsubsection{Problems to be solved by emergency management for military engineering projects}

An analysis of the concept and mode of emergency management shows that in many cases emergency plans fail mainly because of "malpractice of people", "unsafe state of objects", "drawbacks in management and decisionmaking" during a disaster or crisis. Emergency management for military engineering projects is affected by the safety issue of the "object system" for military engineering projects, regulation issues of the "human system" for emergency management, and various management and decision-making factors, such as engineering mode and concept, engineering technique, and operation method. Therefore, emergency plans for military engineering projects must be able to achieve comprehensive, dynamic coordination during the emergency. In other words, plans must resolve the problem of scientific decision-making for uncertain factors in the system.

2.3 Application of comprehensive integration method to emergency management for military engineering projects

2.3.1 Concept of emergency management for military engineering projects

Military engineering involves the planning and construction activities for military defense facilities and their emergency repair and building. It is a critical aspect of national defense strategy and warfare preparation of a 
sovereign state.

Based on this basic theory, emergency management for military engineering projects involves decision-making, organization, construction, control and repair for military facilities. The purpose is to meet the needs of pre-war preparation, wartime response and post-war emergency response. Emergency management embodies the requirements for scientific decision-making for systematic combat and dynamic management. It is an important part and supplement of the systematic combat concept.

\subsubsection{Principle and method of comprehensive integration}

Integration means "gathering and synthesis" and is a process of creatively integrating two or more elements or systems into an organic entity based on a systematic concept. Integration principle, which includes entity optimization, systematic innovation, and functional synergy, reflects a regular pattern that "the whole is greater than the sum of its parts", expressed as " $1+1>2$ ". The integration concept essentially shares the same views with the idea of "system of systems".

2.3.3 Comprehensive integration method for emergency management for military engineering projects

Integration approaches include integrating knowledge, technology and method. Knowledge integration means comprehensive application of knowledge from multiple disciplines. Technical integration means combining two, or more, individual techniques according to a certain technical principle or functional purpose to obtain an integrated technology with uniform functionality. Method integration means integrated measures and structural modes are used to obtain certain objects or achieve certain purposes.

Comprehensive integration method reflects "integration of systems", which means emergency management systems for military engineering projects must be clearly defined. This analysis of basic theory shows that emergency management systems for military engineering projects display two essential features: first, military engineering facilities are a system of elements for military combat, military engineering projects must focus on strengthening of the systematic response capacity of the engineering defense system. Second, military engineering facilities are an emergency support system for military operation. Military engineering projects must achieve dynamic, information technology-based management from the pre-war, wartime and post-war perspectives. In other words, as an engineering support system for the military combat system, military engineering projects must be subjected to "systematic comprehensive integration" and dynamic decision-making, construction and management to achieve emergency management before, during and after an emergency.

\section{Building of emergency management system for military engineering projects}

\author{
3.1 Engineering system and emergency analysis of military \\ combat system
}

Theoretical analysis of emergency management for military engineering projects shows that military engineering projects' emergency management is systematic, dynamic and based on integrated management. As indicated in the U.S. Army's $\mathrm{C}^{4}$ ISR, the combat system includes the operational architectural framework mainly concerned with operational troops system. The architectural framework mainly consists of physical resources, and the technical architectural framework is based on communication support. The composition of an emergency management system for military engineering projects under the combat system analysis is as follows.

\subsubsection{Military combat system and its infrastructure system}

Military combat involves a giant complex system. The upper layer is divided into six systems, including political, military, economic, social, infrastructure and information systems. Each system is divided and simplified into two major elements: node (or decision-making point); and connection. In a system, nodes are actual elements (people, locations, or objects), and connections are the physical, functional, or behavioral relationships between the nodes. Critical nodes are major decisions "related to strategy, or combat result or focus".

The military infrastructure system is normally regarded as the military logistics support system. It is divided into five elements, including comprehensive support, fuel support, health service support, transport support, and engineering support. These elements involve wholeprocess management from decision-making to construction and operation. Similarly, engineering support systems normally consists of three elements: engineering defense, engineering team, and defense command. Military engineering projects involve defense engineering, defense personnel, and defense command. The emergency management system for military engineering projects is an important node in the infrastructure network system for the military combat system.

3.1.2 Military engineering system and its functional elements

Military engineering systems, also called engineering support systems, are military infrastructure facilities built, operated and managed by combat engineers according to the decision of the military system. The structure of the military engineering system reflects its basic functional elements, "system design-node determination", "resource 
utilization-engineering action", and "system support-connection and operation". The level at which "nodes" of system design are determined reflects the degree of completeness of the military combat system. The degree of "physical resource" utilization in the system demonstrates the capability of the system to support combat missions. "Connectivity" with the system that supports the combat function displays the extent of informationalization in combat engineering.

3.1.3 Emergency management for military projects and requirements for building emergency management system

From the systematic combat point of view, military engineering is undoubtedly an important element of the wartime logistics system. It reflects the position and role of military defense facilities in the military decision-making system, demonstrates how to build military engineering facilities, their construction requirements and operational modes during war. As a participating element in war, prewar readiness plans, wartime strategies, and post-war measures must be established for military engineering from the perspective of emergency management. Generally, emergency management systems for military engineering projects proposes the overall requirements for engineering and dynamic control of the military information system to achieve "pre-war preparedness, wartime response, and post-war management" of the defense facilities.

3.2 Framework of emergency management system for military engineering projects

3.2.1 Elements of the emergency management system for military engineering projects

The first part is the engineering defense system, the basic elements of which include functional determination, construction quality, and operation performance. Apparently, the engineering defense system is a physical subject determined, constructed and controlled by humans.

The second part is the support team system, the basic elements of which include support team moral qualities, construction skills, and management performance. Apparently, the support team system is also a motivated organizational system determined by a certain node in the system, constructed by a team at a certain level, and managed by a corresponding team.

The third part is the communication and command system, acting as a planning department for the construction, operation, and emergency management of defense projects during war under military combat system command. Evidently, the communication and command system serves as an important connecting node in the military infrastructure system or even the military combat system.
3.2.2 Relationship of emergency management system for military engineering with other systems

The emergency management system for military engineering is itself an open network system. Its internal system includes three elements: engineering support team, engineering defense, and the connecting element of communication and command. To meet emergency management requirements, three elements must be subjected to pre-war, war, and post-war comprehensive management according to the form of the war. Meanwhile, in the external systems, military competition and dynamic decision-making formed by the destruction techniques of different weapons, i.e., the high-level military combat system, determines corresponding defensive engineering teams, project technologies, as well as the construction, control, operation and management modes, and decides the elements of the emergency management system for military engineering projects from a dynamic decision-making aspect.

\subsubsection{Structure of the emergency management system for} military engineering projects

As mentioned above, military engineering personnel participate in the war as a logistics combat system consisting of the support team system, the engineering defense system, and the communication and command system under the influence of external systems. The way in which military engineering participates in wartime emergency response is determined by dynamic decisionmaking, construction techniques, and the management strategy of the combat engineering system during pre-war, wartime, and post-war stages. Based on the comprehensive integration method for a system, the emergency management system for military engineering is a "strategic response, integration and control" architectural framework formed by the combat engineering system through "prewar intelligent construction, wartime early warning and monitoring, and post-war repair and maintenance" of the information systems. This is an integrated system mode consisting of three stages and three-dimensional elements.

3.3 Integration of the emergency management system for military engineering

3.3.1 Integration of the support team system with the engineering defense system

A potent and effective support team must be an excellent team with a high moral quality, outstanding construction skills, and fine working style. Team members obey organizational decisions, meet wartime personnel requirements, and understand advancements in weaponry. They effectively identify, design, and construct the offensive properties of weaponry and defensive properties of 
facilities. Support team members meet the requirements of informationalization and conduct intelligent design, early warning, monitoring, and emergency response for engineering defense facilities. During the decision-making stage, information technology is used for engineering defense facilities to conduct informationalized design and construct engineering infrastructure facilities. According to the decision-making requirements, important structures, defensive positions, and lifelines of engineering defense facilities are equipped with sensing equipment and are constructed in an intelligent manner, and a complete project management information system is established to achieve visualized operation. Accordingly, the support team further develops defense construction, operation, and management rules for the information system and conducts technical drills, early warning tests, and dynamic decision-making management to avoid errors in the emergency plans for the "human system" and the "object system" and achieve dynamic emergency management for military engineering projects.

3.3.2 Integration of the engineering defense system with the communication and command system

As mentioned above, to achieve emergency management for military construction projects, engineering defense facilities must be able to achieve "on-demand design, wartime monitoring and emergency response". The support team system should be able to achieve intelligent construction of the engineering defense facilities and information monitoring. In addition, early warning information about the defense projects also must be integrated with the military command information. As a uniform decision-making organ within the system, the military command system is under the command of the military combat system and is concerned with whether the military combat system develops toward "resistant" defense, "comprehensive" defense, or "active" counterattack. The effective integration of the engineering defense system within the communication and command system is required to avoid errors in "decision-making and command".

3.3.3 Integration of the support team system, and the engineering defense system with the communication and command system

If the function of the defense team system is simplified to mean protecting the "human system" and the function of the engineering defense system is simplified to mean protecting the "object system", to achieve pre-war preparedness, wartime response, and post-war emergency response, evaluation and handling of the management system for military construction projects, the "human system" measures of the defense team system, and the "object system" measures of the engineering defense system must be integrated with the communication and command system to adapt to the external military combat system, and obtain synergic effects on the internal systems so as to finally achieve the goal of "pre-war preparedness, wartime response, and post-war emergency response" for the emergency management system for military engineering projects.

\section{Conclusions}

Military engineering and emergency management are complex systems. Emergency management of military engineering projects is a larger, and more complex, giant system. In this study, in response to the new trend in emergency management for military engineering projects under information warfare, the systematic combat concept and integration management approaches were used to preliminarily investigate the three-stage, three-dimensional integration architectural framework for emergency management for military engineering projects. Also, a basic mode of emergency management for military engineering projects themed "pre-war intelligent construction on demand, wartime early warning and monitoring, post-war emergency repair and rescue" and "strategic, comprehensive, integrated response" is proposed. This study is just a preliminary exploration on emergency management for military engineering projects to adapt the systematic combat concept. With the development of military engineering projects and emergency management information systems, an information network for the military logistics and combat system should be established and further study and research is needed on the specific approaches for emergency management of military engineering projects. 